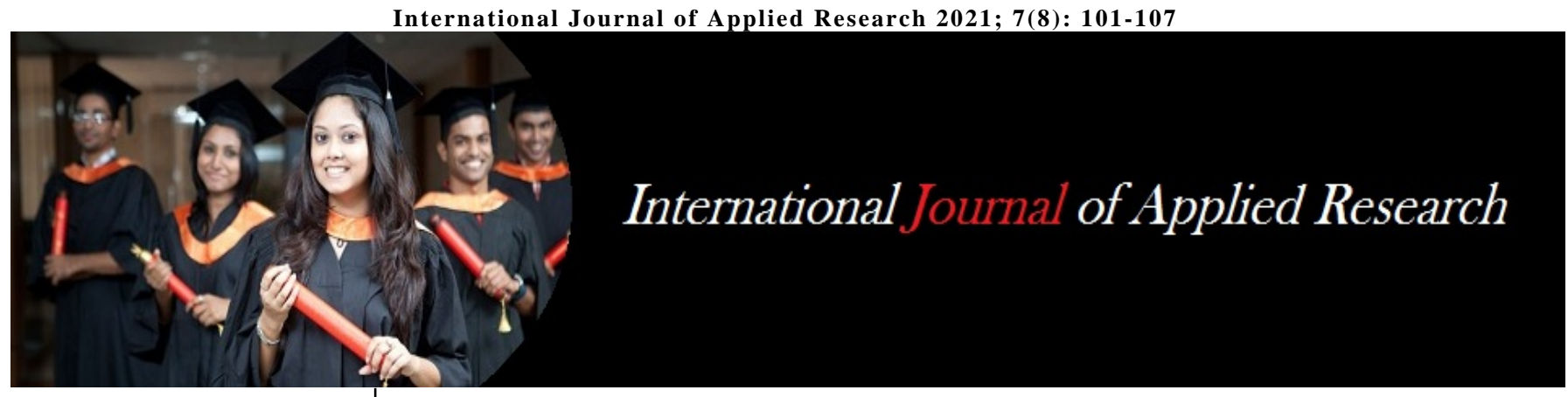

ISSN Print: 2394-7500 ISSN Online: 2394-5869 Impact Factor: 8.4 IJAR 2021; 7(8): 101-107 www.allresearchjournal.com

Received: 16-06-2021 Accepted: 18-07-2021

Sheleme Gofe Keneni Department of Physical Education, Mangalore University, Mangalagangothri, Mangalore, Karnataka, India

Gerald Santhosh D'Souza Department of Physical Education, Mangalore University, Mangalagangothri, Mangalore, Karnataka, India

Corresponding Author: Sheleme Gofe Keneni Department of Physical Education, Mangalore University, Mangalagangothri, Mangalore, Karnataka, India

\section{Sport science university students physical activity level according to IPAQ}

\section{Sheleme Gofe Keneni and Gerald Santhosh D’Souza}

\author{
DOI: https://doi.org/10.22271/allresearch.2021.v7.i8b.8834
}

\section{Abstract}

The worldwide decline in physical activity and the increase in sedentary and obesity have been discussed in several studies. For most nations, inactivity at various ages is a serious issue. The aim of the study was to investigate the physical activity level and variances among sport science students at the university of Oromia State, Ethiopia, in relation to sex. Self administrated International Physical Activity Questionnaire (IPAQ) short form was used by students to self-report their amount of physical activity. A total of 266 students (133 male, 133 female) with an average age of $22.88 \pm 2.41$ years were participated at this study. The results of present study showed that males showed a higher percentage (54.1\%) of high physical activity level than females (9.0\%). Females displayed a high percentage (51.1\%) of low level of physical activity compared to males $(11.3 \%)$. Participants in the age range of 22-25 years indicated more percentage (44.9\%) of high physical activity level. When the levels of physical activity assessment were done based on academic achievements, great distinction ( $\geq 3.6 \mathrm{GPA})$ students showed the highest percentage $(72.3 \%)$ of high physical activity level. Students who were normal body weight depicted high percentage (41.9\%) of high physical activity level. Moreover, students who have positive attitude towards physical activity showed the highest percentage (88.6\%) of high physical activity level. It is concluded that in this group of students the physical activity level is sufficient and that there is a lower physical activity among females than males. It is essential to constantly take actions and select students based on their interest and sport skills for promoting physical activity and sports participation at colleges with the goal of improving students' health status to a higher degree.

Keywords: IPAQ-short, physical activity level, body mass index, university students

\section{Introduction}

Several studies have taken into account the global decline in physical activity and the increase in the risk of obesity and other diseases, such as cardiovascular disorders, cancer, type 2 diabetes, hypertension, obesity, osteoporosis, and depression ${ }^{[1]}$. Research shows that regular physical activity can minimize these risks and play an outstanding role in building and sustaining strong bones and muscles, reducing obesity, reducing stress and anxiety, alleviating symptoms of depression, and promoting well-being and healthy lifestyles [2]. Physical inactivity and obesity have caused about 2.8 million deaths worldwide per year ${ }^{[3]}$. A decreased risk of all-cause mortality, reduced risk of developing cardiovascular disorders, cancer, type 2 diabetes, hypertension, obesity, osteoporosis, and depression have been associated with higher physical activity levels. Researchers indicate that shortage of physical activity participation and prolonged engagement in sedentary behaviors results in obesity which leads to the prevalence of many severe health conditions, such as cardiovascular disease, breast cancer, colon cancer, and type II diabetes, high cholesterol and stroke ${ }^{[4,5]}$. Studies have shown that daily engagement in physical activity has a positive impact on physical, social and mental well-being ${ }^{[6,7]}$. It decreases the risk of chronic disease development, increases the quality of life and well-being, and enhances cognitive functioning $[8,9]$. Getting physically active will reduce the rates of illness and promote a healthier lifestyle because prevention is better than treatment. Physical activity increases sleep efficiency. An individual who is physically fit is easier to sleep and feel active throughout the day and reduces insomnia. 
Regardless of the proof of these comprehensive advantages, in order to reap the potential benefits, many nevertheless do not meet the recommended amount of physical activity. Researchers pointed out that rising daily physical activity for physically inactive individuals should be a primary concern of the public health matter for people of all ages in addition to college sport science students ${ }^{[10]}$.

It has been observed that during the transition of adolescents to young adulthood, the decline in physical activity and rise in sedentary behavior was noticeable with the steepest decrease occurring at the time of college entry, recognizing that one-third of active high school students were insufficiently active during the transition to college life ${ }^{[11]}$. Previous research on gender disparities have shown that there is a distinct physical activity relationship between men and women, and women are far less likely than males to participate in different daily physical activity programs. There was a 21.4 percent prevalence of physical inactivity in the world, higher among women than among men. Research shows that one in five adults in the world is perceived to be inactive physically ${ }^{[12]}$. Even though physical inactivity observed in both males and females, there is a substantially higher degree of physical inactivity in females than in males. A study showed that gender has major physical activity associations in which males are more involved in physical activity than females ${ }^{[13]}$. The study of gender differences shows that there are different reasons for females and males to engage in physical activity. Research found that male students were motivated by internal incentives such as strength, competitiveness and challenges, whereas external reasons such as weight control and attractiveness motivated female students to take part in physical activity ${ }^{[14]}$. Due to increased physical inactivity, especially among young adults of college students, approaches should be encouraged to increase the level of physical activity and to decrease sedentary behavior ${ }^{[15]}$. A significant barrier to a balanced lifestyle is the constant use of the Internet, Facebook, and watching television; accordingly, only a small proportion of college students participate in daily physical activity programs [16]. Therefore, all healthy young people aged 18 - 64 years should perform moderate physical activity for at least 30 minutes 5 days a week or intense physical activity for at least 20 minutes 3 days a week, according to the recommendations of the American College of Sports Medicine, to maintain optimal health and well-being for their lives ${ }^{[17]}$. Research has shown that students' academic performance can be enhanced if they were physically active [18]. The International Physical Activity Questionnaire (IPAQ) was established to help experts solve physical activity or inactivity issues in 1998 to promote physical activity testing based on the global norm ${ }^{[19]}$. This questionnaire has since been one of the most widely used for physical activity ${ }^{[20]}$. College sports science students have found poor physical activity habits resulted in overweight or obesity, which is unhealthy body mass indexes ${ }^{[21]}$.

Today, one of the key conditions for human beings survival is certainly the need for daily physical activity. The level of physical activity of college sport science students is decreasing and the risks of obesity and other diseases are increasing, which are considered to be the world's serious problems. It is therefore important to inspire strategies that increase the understanding of fitness, knowledge, and significance of physical activity. Hence, it is not surprising that the problem of physical activity and obesity has recently become one of several global researchers' most popular study topics and challenges ${ }^{[22]}$. Considering the high prevalence of low levels of physical activity among sport science students, this is a good opportunity for all college students to examine their current lifestyle. Accordingly, the aim of this study was to determine the level of physical activity and differences in sex among sport science professional students at the university level.

\section{Material and Method}

\subsection{Study Participants}

This study conducted on a total sample of 266 students, specializing in sport sciences. All the study participants were healthy without any previous medical condition to avoid being physically active and completing the surveys. Out of the total number of students, 133 were male (mean age $22.76 \pm 2.42$ ) and 133 female (mean age $23.01 \pm 2.40$ ) of the second and third year of study.

\subsection{Recruitment}

All students signed an informed consent form for their participation in the study. The study was voluntary, and the students were not given incentives. The study included participants between 18-30 years of age, both physically active and inactive. The researcher omitted study participants with a physical or psychological disability and physical activity contraindications.

\subsection{Materials (Study Instrument)}

The International Physical Activity Questionnaire (IPAQ) short form was used to determine the level of physical activity among students ${ }^{[23]}$. The short version of the IPAQ has acceptable test-retest reliability and validity for sitting and vigorous physical activity ${ }^{[24]}$. The IPAQ defines physical activity (PA) in units of energy consumptionminutes per week. It calls for 3 different forms of physical activities, such as walking, moderate-intensity, and vigorous-intensity activities performed in four domains. Scientific studies note that one Metabolic Equivalent (MET) is equivalent to approx. $3.5 \mathrm{ml}$ of oxygen per min-1 kg-1 body weight. One MET = a resting energy expenditure assuming a $3.5 \mathrm{ml}-\mathrm{min} / \mathrm{kg}$ oxygen intake. Walking $=3.3$ METS, moderate-intensity PA $=4.0$ METS and vigorousintensity PA $=8.0$ METS. The following 3 categories were identified in the IPAQ weekly PA category score evaluation framework:

A. High PA level: Considering this expenditure is the effect of vigorous-intensity activity on at least 3 days achieving a minimum total physical activity (PA) of at least $1500 \mathrm{MET}$-minutes/week; 7 or more days of any combination of walking, moderate or vigorous-intensity activities which achieve a minimum total PA of at least 3000 MET-minutes/week.

B. Moderate PA level: Considering this expenditure is the effect of 3 or more days of vigorous-intensity PA for a minimum of 20 minutes daily; 5 or more days of moderate-intensity PA and/or walking for at least 30 minutes/day; 5 or more days of any combination of walking, moderate/vigorous PA attaining a minimum total PA not less than $600 \mathrm{MET}$-minutes/week.

C. Low PA level: Considering when the total energy outlays below 600 MET-minutes/weeks. 


\subsection{Procedure}

All study participants were involved in anthropometric (height and weight) assessments before submitting the questionnaire according to standard methods suggested by the International Society for the Advancement of Kinanthropometry ${ }^{[25]}$. Based on these measurements, the researcher determined the body mass index (BMI) by using the formula: weight $(\mathrm{kg}) /$ height $^{2}(\mathrm{~m})$. The participants' age and sex were also recorded. Before beginning the survey, respondents were asked to complete the questionnaire as accurately and honestly as possible, because this survey was voluntary. Questionnaires were issued with the same evaluators being present at all times. A brief explanation was given to participants prior to filling in the questionnaires, in which they were told about: (i) answering items thinking about a typical week, rather than about the previous week, and (ii) the differences between vigorous and moderate activities. Then participants took the survey questionnaires when they arrived at the sports hall and began to answer questions with help at any time with possible ambiguities after explanation and clear information on the study, the goals, and the mode of implementation. An

evaluation of the level of PA was performed using the IPAQ short form in which respondents are asked to record the number of days and duration of vigorous, moderate, and walk. All PA score levels were measured in METminutes/week (www.ipaq.ki.se). Values used to interpret IPAQ data were: Walking MET $=3.3 \mathrm{x}$ walking minutes/day x walking days/week, Moderate MET $=4.0 \mathrm{x}$ walking minutes/day $\mathrm{x}$ walking days/week, and Vigorous $\mathrm{MET}=8.0 \mathrm{x}$ walking minutes/day $\mathrm{x}$ walking days/week.

\subsection{Data Analysis}

Data were analyzed by descriptive statistical method (Mean, SD - standard deviation and Frequencies) for each study participants using Microsoft excel 2010 and SPSS 20 version. Anthropometric measurements, frequency and duration of vigorous physical activity, moderate physical activity and walking are presented as mean \pm SD and means were compared between genders by using Independent Samples t- test accepting a significant level of 5\%.

\section{Results}

Table 1: Anthropometrics Measurement of the Study Participants Arranged by Gender

\begin{tabular}{|c|c|c|c|c|}
\hline Anthropometrics & Total $(\mathbf{n}=\mathbf{2 6 6})$ & Males (n=133) & Females (n=133) $^{\text {P-Value }}$ \\
\hline Age (years) & $22.88 \pm 2.41^{\mathrm{a}}$ & $22.76 \pm 2.42^{\mathrm{a}}$ & $23.01 \pm 2.40^{\mathrm{a}}$ & $\mathrm{ns}$ \\
\hline Height $(\mathrm{m})$ & $1.62 \pm 0.07$ & $1.69 \pm 0.07$ & $1.56 \pm 0.08$ & 0.000 \\
\hline Weight $(\mathrm{Kg})$ & $59.35 \pm 4.55$ & $65.55 \pm 5.02$ & $53.14 \pm 4.07$ & 0.000 \\
\hline BMI $\left(\mathrm{kg} / \mathrm{m}^{2}\right)$ & $22.55 \pm 1.78$ & $23.05 \pm 1.61$ & $22.05 \pm 1.96$ & 0.000 \\
\hline
\end{tabular}

The results of anthropometric data in Table 1 show that male students were higher, heavier and had a higher body mass index. There were also no significant differences in age between the male and female study participants.

Table 2: Demographic Characteristics of the Study Participants

\begin{tabular}{|c|c|c|}
\hline \multicolumn{2}{|c|}{ Variables } & $\mathrm{N}(\%)$ \\
\hline \multirow{3}{*}{ Gender } & Male & $133(50)$ \\
\cline { 2 - 3 } & Female & $133(50)$ \\
\hline \multirow{3}{*}{ Age } & $18-21$ & $78(29.3)$ \\
\cline { 2 - 3 } & $22-25$ & $167(62.8)$ \\
\cline { 2 - 3 } Body Mass Index (BMI) & $26-30$ & $21(7.9)$ \\
\cline { 2 - 3 } & Under weight & $18(6.8)$ \\
\cline { 2 - 3 } & Normal & $234(87.9)$ \\
\cline { 2 - 3 } & Overweight & $12(4.5)$ \\
\hline \multirow{4}{*}{ Physical Activity Level } & Obese & $2(0.8)$ \\
\cline { 2 - 3 } & High & $38(14.3)$ \\
\cline { 2 - 3 } & Moderate & $149(56.0)$ \\
\hline \multirow{3}{*}{$\begin{array}{c}\text { Academic Achievement } \\
\text { (GPA) }\end{array}$} & Low & $79(29.7)$ \\
\cline { 2 - 3 } & $2.0-2.5$ & $33(12.4)$ \\
\cline { 2 - 3 } & $2.6-3.1$ & $88(33.1)$ \\
\cline { 2 - 3 } & $3.2-3.5$ & $80(30.1)$ \\
\hline \multirow{2}{*}{ Attitudes } & $\geq 3.6$ & $65(24.4)$ \\
\cline { 2 - 3 } & Positive Attitude & $35(13.2)$ \\
\cline { 2 - 3 } & Negative Attitude & $231(86.8)$ \\
\hline
\end{tabular}

$\mathrm{N}$ : frequency, \%: Percentage.

As indicated in table 2 the study participants consisted of $50 \%(n=133)$ female students and 50\% ( $n=133)$ male students. The results of physical activity level data in Table 3 show that there were 15(11.3\%) male participants observed in the low physical activity category, 46(34.6\%) in the moderate physical activity category and $72(54.1 \%)$ indicated high physical activity. In the meantime, there were
68(51.1\%) female participants who demonstrated low physical activity, 53(39.9\%) and $12(9.0 \%)$ females who showed moderate and high physical activity levels, respectively. The study participants were categorized into 3 ranges of age as $18-21$ years, $22-25$ years and $26-30$ years. Amid study participants in the 18-21 age range, 15(19.2\%) fall into high physical activity level, 21(26.9\%) in the moderate physical activity level and 42(53.9\%) in the low physical activity level. In the 22-25 age range, $75(44.9 \%)$ seen in the high, 63(37.7\%) in the moderate and $29(17.4 \%)$ in the low physical activity level. In the last age range, $8(38.1 \%)$ of them demonstrated high physical activity level, whereas, 11(52.4\%) and 2(9.5\%) showed moderate and low physical activity levels, respectively. The study participants were classified into 4 ranges of academic achievement as fair (2.0 - 2.4 GPA), satisfactory (2.5 - 3.0 GPA), distinction (3.2 - $3.5 \mathrm{GPA})$ and great distinction ( $\geq 3.6$ GPA). Among study participants in the fair academic achievement range, $0(0 \%)$ students showed high physical activity level, 7(21.2\%) moderate physical activity level and 26(78.8\%) low physical activity level. In the satisfactory academic achievement range group, $8(9.0 \%)$ students were seen in the low physical activity level, whereas, 40(45.5\%) were seen in both high and moderate levels of physical activity level. In the distinction academic achievement category, 42(52.5\%) demonstrated high physical activity level, whereas, 28(35.0\%) and 10(12.5\%) showed moderate and low physical activity levels, respectively. In the great distinction academic achievement range category, $47(72.3 \%)$ of them showed high physical activity level, whereas, $13(20.0 \%)$ and 5(7.7\%) demonstrated moderate and low physical activity levels, respectively. 
When the characteristics of the study participants were analyzed based on their body mass index, 0(\%) students were seen to fall under the underweight group in the high physical activity level, whereas, 2(11.1\%) and 16(88.9\%) underweight students were seen in the moderate and low physical activity levels respectively. Most of the students were in the normal body mass index among them 98(41.9\%) were seen in the high physical activity level, 109(46.6\%) in the moderate and $27(11.5 \%)$ in the low physical activity level. Some of the students were also seen in the overweight body mass index classification. Amid them, $0(0 \%)$ had high physical activity levels, 5(41.7\%) had moderate physical activity levels and 7(58.3\%) had a low level of physical activity levels. A very few students were seen in the obese body mass index group. Among them, only 2(100\%) demonstrated low physical activity level. There were no, $0(0 \%)$ obese students who demonstrated high and moderate physical activity level. When the characteristics of the study participants were analyzed based on their attitude towards physical activity, 31(88.6\%) students were seen to grouped under positive attitude in the high physical activity level, whereas, 4(11.4\%) students who have positive attitude were seen in the moderate physical activity level. There were no, $0(\%)$ positive attitude students who demonstrated low physical activity level. The majority of the students have negative attitude towards physical activity. Among them, $0(0 \%)$ students were seen in high, $15(6.5 \%)$ in moderate and 216(93.5\%) in low physical activity level.

Table 3: Frequency Results of Physical Activity Level Based on IPAQ Survey data for Category Score N (\%)

\begin{tabular}{|c|c|c|c|c|}
\hline \multirow{2}{*}{\multicolumn{2}{|c|}{ Variables }} & \multicolumn{3}{|c|}{ Category Score } \\
\hline & & High & Moderate & Low \\
\hline \multirow{2}{*}{ Gender } & Male & $72(54.1)$ & $46(34.6)$ & $15(11.3)$ \\
\hline & Female & $12(9.0)$ & 53 (39.9) & 68 (51.1) \\
\hline \multirow{3}{*}{ Age } & $18-21$ & $15(19.2)$ & $21(26.9)$ & $42(53.9)$ \\
\hline & $22-25$ & $75(44.9)$ & $63(37.7)$ & $29(17.4)$ \\
\hline & $26-30$ & $8(38.1)$ & $11(52.4)$ & $2(9.5)$ \\
\hline \multirow{4}{*}{ Body Mass Index (BMI) } & Underweight & $0(0)$ & $2(11.1)$ & $16(88.9)$ \\
\hline & Normal & $98(41.9)$ & $109(46.6)$ & $27(11.5)$ \\
\hline & Overweight & $0(0)$ & $5(41.7)$ & $7(58.3)$ \\
\hline & Obese & $0(0)$ & $0(0)$ & $2(100)$ \\
\hline \multirow{4}{*}{$\begin{array}{c}\text { Academic Achievement } \\
\text { (GPA) }\end{array}$} & $2.0-2.5$ & $0(0)$ & $7(21.2)$ & $26(78.8)$ \\
\hline & $2.6-3.1$ & $40(45.5)$ & $40(45.5)$ & $8(9.0)$ \\
\hline & $3.2-3.5$ & $42(52.5)$ & $28(35.0)$ & $10(12.5)$ \\
\hline & $\geq 3.6$ & $47(72.3)$ & $13(20.0)$ & $5(7.7)$ \\
\hline \multirow{2}{*}{ Attitudes } & Positive Attitude & $31(88.6)$ & $4(11.4)$ & $0(0)$ \\
\hline & Negative Attitude & $0(0)$ & $15(6.5)$ & $216(93.5)$ \\
\hline
\end{tabular}

$\mathrm{N}$ : frequency, \%: percentage.

The weekly frequency (number of days) of vigorous physical activities, moderate physical activities and walking in the last 7 days between male and female study participants were shown in table 4 with mean and standard deviation through international physical activity questionnaire (IPAQ) short form of question number 1, 3, and 5. After studying Table 4 we can say that male subjects often participate on more days of vigorous physical activity, moderate physical activity, and walking than the female subjects.

Table 4: Weekly frequency of vigorous physical activities, moderate physical activities and walking in last 7 days between male and female participants.

\begin{tabular}{|c|c|c|c|c|}
\hline Questions & Total (n= 266) & Males $(\mathbf{n}=\mathbf{1 3 3})$ & Females $(\mathbf{n}=133)^{\text {P-Value }}$ \\
\hline No of days of vigorous PA & $2.62 \pm 1.75^{\mathrm{a}}$ & $3.56 \pm 1.83^{\mathrm{a}}$ & $1.68 \pm 1.03^{\mathrm{a}}$ & 0.000 \\
\hline No of days of moderate PA & $2.57 \pm 1.41$ & $3.31 \pm 1.32$ & $1.83 \pm 1.08$ & 0.000 \\
\hline No of days of Walking & $5.46 \pm 1.24$ & $5.88 \pm 1.11$ & $5.03 \pm 1.22$ & 0.000 \\
\hline
\end{tabular}

${ }^{\mathrm{a}}$ Mean $\pm \mathrm{SD}$, *=independent sample t-test

The weekly duration of vigorous physical activities, moderate physical activities and walking in the last 7 days between male and female study participants were shown in table 5 with mean and standard deviation through international physical activity questionnaire (IPAQ) short form of question number 2, 4, 6, and 7. After studying Table 5 we can say that the time spent on vigorous physical activity, moderate physical activity, walking and sitting was higher to the male subjects than the female subjects.

Table 5: Weekly duration of vigorous physical activities, moderate physical activities and walking in last 7 days between male and female participants.

\begin{tabular}{|c|c|c|c|c|}
\hline Questions & Total $(\mathrm{n}=266)$ & Males $(\mathrm{n}=133)$ & Females $(\mathrm{n}=133)$ & P-Value $^{*}$ \\
\hline Duration of Vigorous PA & $4.38 \pm 3.43^{\mathrm{a}}$ & $6.48 \pm 3.46^{\mathrm{a}}$ & $2.28 \pm 1.65^{\mathrm{a}}$ & 0.000 \\
\hline Duration of Moderate PA & $4.57 \pm 2.64$ & $6.03 \pm 2.29$ & $3.12 \pm 2.12$ & 0.000 \\
\hline Duration of Walking & $7.23 \pm 2.62$ & $8.62 \pm 2.67$ & $5.85 \pm 1.67$ & 0.000 \\
\hline Duration of Sitting & $19.45 \pm 5.72$ & $20.95 \pm 6.09$ & $17.95 \pm 4.91$ & 0.000 \\
\hline
\end{tabular}

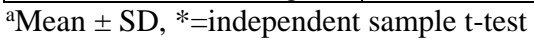




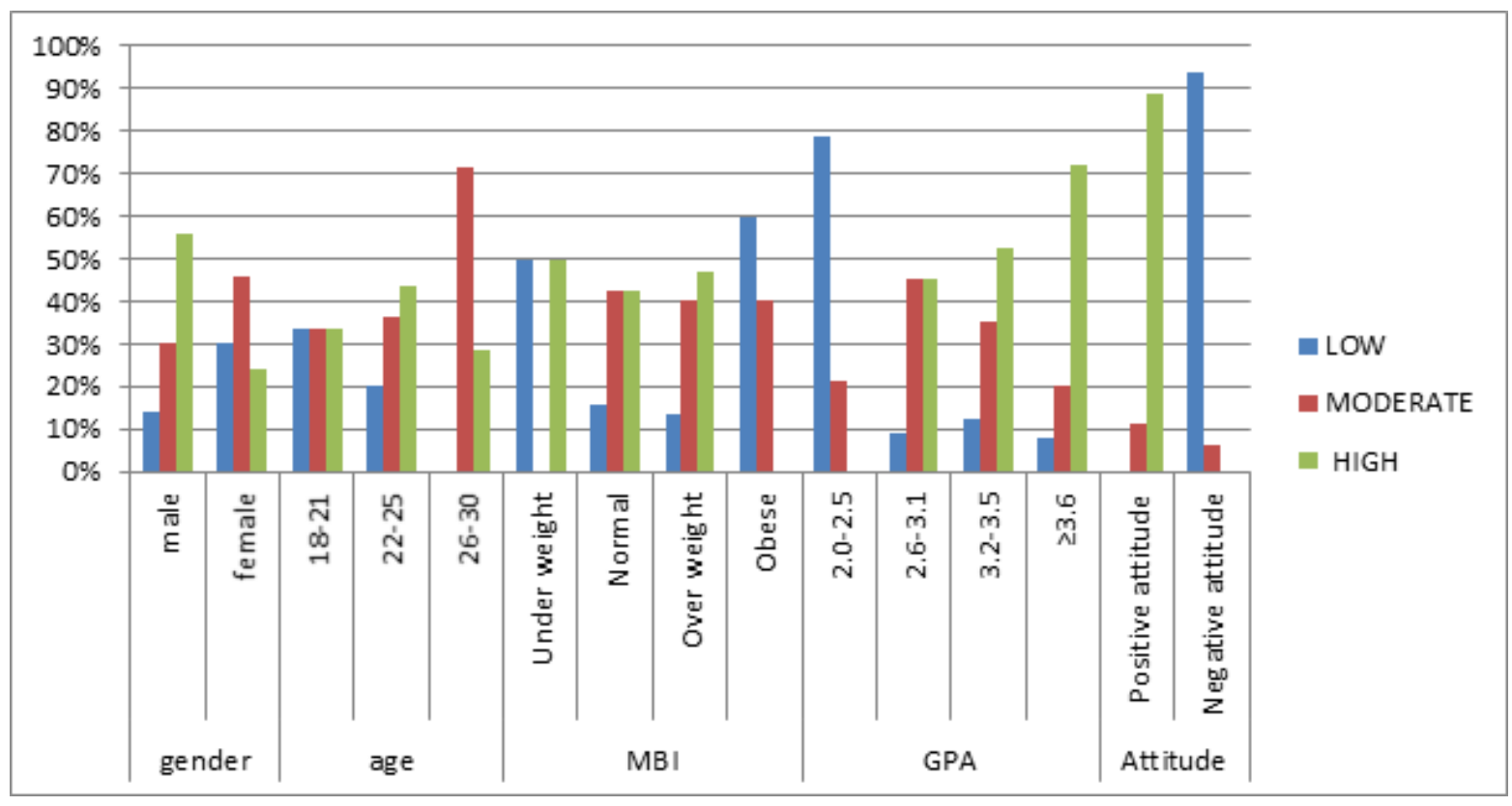

Graph 1: Physical activity level of the study participants on the basis of variables.

\section{Discussion}

This study was conducted using the short version of the International Physical Activity Questionnaire (IPAQ) to identify the level of physical activity and differences among university sport science students of Oromia State, in relation to gender. 266 college sport science students were selected for this study consisting of 133 male and 133 female students with age ranges from 18 to 30 years. Gender is well-thought-out as one of the most significant predictors of physical activity. Numerous studies revealed that physical activity levels among adolescence varied based on genders in which males demonstrated a higher percentage of physical activity than females. Previous studies have also been shown that female adolescence was less physically active than male adolescence ${ }^{[26-29]}$. The crude global occurrence of low level of physical activity was $21.4 \%$ being higher among women $(23.7 \%)$ than men $(18.9 \%){ }^{[10]}$. Likewise, the results of the present study also indicated that male students are more physically active than female students. The percentage of low level physical activity of both male and female participants was $11.3 \%$ and $51.1 \%$ respectively. Study from authors ${ }^{[30]}$ and ${ }^{[31]}$ also confirm the current findings that women engage in less physical activity than men, which may be motivated by perception of predominant exercise [32]. The result of the current study also found that there is a difference in the level of physical activity between the ages. A previous study ${ }^{[33]}$ confirms the current findings that the level of physical activity varies in between the age ranges. Students at the age range of 22-25 demonstrated the highest high level of physical activity compared with students in an age range of 18-21 and 26-30. The current study also showed that the physical activity level is associated with body mass index (BMI) status. The distribution of respondents with high physical activity level was found in normal BMI groups. This finding is in agreement with a study which has shown that overweight Malaysian adolescents were found to be physically active than normal weight adolescents ${ }^{[34]}$. High percentage of low physical activity level was found in obese and underweight BMI groups compared with other BMI groups. But, a previous study ${ }^{[27]}$ found that no relationship between physical activity level and weight status. It has been reported that regular participation in physical activity improves the academic achievement of the students. The current study findings also indicated that the physical activity level is associated with academic achievement/performance of the students. The distribution of respondents with high physical activity level was found in the great distinction academic achievement category. This finding is agreed with previous studies ${ }^{[35-37]}$ which have shown that there is a significant positive relationship between students' physical activity habits and high-GPA achievement. Referring to result obtained by other author ${ }^{[38]}$ also suggested that increasing the time spent in physical activity at school increased academic performance in comparison with students who had no additional activity. The findings of the present study depicted that the physical activity level is linked with the outlook of the students towards physical activity. The distribution of respondents with high physical activity level was found among students who had positive attitude towards physical activity.

\section{Conclusion}

The results obtained from the present study indicated that the higher percentage of low physical activity level was observed among female than male students. Moreover, underweight and obese body weight status students showed a low level of physical activity in a higher percentage. The findings stated in this study depicted that it is essential to constantly take actions and recruit students based on their interest and sport skills for promoting level of physical activity with the aim of raising the health status of students to a higher level. Even though the study participants were expected to take part in regular physical activity at higher level and exemplary for others, it is concluded that the level of physical activity of sport science students could be considered as satisfactory.

\section{Recommendation}

The level of physical activity among female respondents was lower than male respondents; it is therefore recommended to design physical activity programs 
especially for the females and incorporate throughout the whole study period among their students to raise the overall level of physical activity. It is also recommended that objective measures of physical activity level might be included to reduce the self-reported approximation error. Sport science students could be recruited based on their sport skills and performance. Also, department of sport science could be tailored to the interests of students in universities helps them to maintain an active lifestyle and have a higher level of physical activity which can positively affect their health and quality of life.

\section{Study Limitations}

The feasible limits of this study were less sample size, probability of recall biases/over reporting of physical activity that directed to overestimation of physical activity levels. Moreover, the sample was restricted to second and third year students who had university experience in specializing sport science, while students from other first year of study did not have university experience within sport science program and they also did not participate in the study.

\section{Acknowledgement}

We would like to extend our heartfelt thanks to all the participants of the study and sport science principals for their support towards the successful completion of this research project.

\section{References}

1. WHO. Global recommendation on physical activity for health 2010; Accessed August 12, 2020.

2. El-Gylany AH, Badawi K, El-Khawaga G, Awadalla N. Physical activity profile of students in Mansoura University, Egypt, Eastern Mediterranean. Health Journal 2011;17(8):694-702.

3. WHO. Obesity and overweight Fact sheet $\mathrm{N}^{\circ} 311$ Updated 2013. Retrieved from:

http://www.who.int/mediacentre/factsheets/fs311/en/ind ex.html.

4. Kohl HW. Physical activity and cardiovascular disease: Evidence for a dose response. Medical Science Sports Exercise Journal 2001;33(6):472-483.

5. Reiner M, Niermann C, Jekauc D, Woll A. Long-term health benefits of physical activity--a systematic review of longitudinal studies. BMC Public Health 2013;13:813.

6. Janssen I, LeBlanc AG, Kannus P, Rimpela A, Legg C, Lumb A et al. Systematic review of the health benefits of physical activity and fitness in school-aged children and youth. International Journal of Behavioral Nutrition Phys Act 2010;7(1):1479-5868-7-40

7. Grosclaude M, Ziltener JL. Benefits of physical activity. Rev Med Suisse 2010;6(258):1495-1498.

8. Verret C, Guay MC, Berthiaume C, Gardiner P, Beliveau L. A physical activity program improves behavior and cognitive functions in children with ADHD: an exploratory study. Journal of Attention Disorder 2012;16(1):71-80.

9. Scheewe TW, Backx FJG, Takken T, Jörg F, van Strater ACP, Kroes AG et al. Exercise therapy improves mental and physical health in schizophrenia: a randomized controlled trial. Acta Psychiatr Scand. 2017;127(6):464-473.
10. Tudor-Locke CE, Myers AM, Rodger NW. Development of a theory-based daily activity intervention for individuals with diabetes II. Diabetes Education. 2001;27(1):85-93.

11. Bray SR, Born HA. Transition to university and vigorous physical activity: Implications for health \& psychological wellbeing. J Amer. College Health. 2004;4(52):181-188.

12. Dumith SC, Hallal PC, Reis RS, Kohl III HW. Worldwide prevalence of physical inactivity and its association with human development index in 76 countries. Preventive Medicine. 2011;53:24-28.

13. Salamuddin N, Harun MT. Physical activity index among Malaysian youth. Asian Social Science. Aug; 2013;9(12):99-104.

14. Egli T, Bland HW, Melton BF, Czech DR. Influence of Age, Sex, and race on college Students' motivation of physical activity. J Am. College of Health 2011;59(5):399-406.

15. Dietary guidelines for Americans. USA: Department of Health \& Human Services 2010.

16. Madell D, Muncer S. Gender differences in the use of the internet by English secondary school children. Social Psychology of Education 2004;7(2):229-251.

17. Haskell et al. Physical Activity and Public Health: Updated Recommendation for Adults From the ACSM and the American Heart Association. Medicine and Science in Sports and Exercise. 2007;39(8):1423-1434.

18. Kamal AA, Yusari N. Malaysian students' involvement in physical activity and impact on academic achievement. Standard J of Education \& Essay. Apr; 2014;2(1):32- 38.

19. Craig CL et al. International Physical Activity Questionnaire: 12-country reliability and validity. Medicine and Science in Sports and Exercise 2003;35:1381-1395.

20. Van Poppel MNM, Chinapaw MJM, Mokkink LB, van Mechelen W, Terwee CB. Physical activity questionnaires for adults: A systematic review of measurement properties. Sports Medicine 2010;40:565600.

21. Brevard PB, Ricketts CD. Residence of college students affects dietary intake, physical activity and serum lipid levels. $\mathrm{J}$ of American Dietetic Association 1996;96(1):35-38.

22. Wang Y, Lobstein T. Worldwide trends in childhood overweight and obesity. International Journal of Pediatric Obesity 2006;1:11-25.

23. International Physical Activity Questionnaire, scoring protocol. Available at:

http://www.ipaq.ki.se/scoring.htm. Accessed December 28, 2020).

24. Kurtze N, Rangul V, Hustvedt BE. Reliability and validity of the international physical activity questionnaire in the Nord Trondelag health study population of men. BMC Medical Research Methodology 2008;8(63)

25. ISAK International Physical Activity Questionnaire 2001. website. www.ipaq.ki.se.

26. Salamuddin N, Harun MT. Physical activity index among Malaysian youth. Asian Social Science 2013;9(12):99-104.

27. Dan SP, Mohd Nasir MT, Zalilah MS. Determination of factors associated with physical activity levels among 
adolescents attending school in Kuantan, Malaysia. Malaysia J of Nutrition 2011;17(2):175-187.

28. Ying CY et al. Prevalence and factors associated with physical inactivity among Malaysian adults. Southeast Asian Journal of Tropical Medicine of Public Health. 2014;45(2):467-480.

29. Mohammed G, Md Said S, Ariffin AA, Kamaruzaman J. Physical inactivity and its associated factors among university students. IOSR Journal of Dental and Medical Sciences 2014;13:119-130

30. Bergier J, Kapka-Skrzypczak L, Bilinski P, Paprzycki P, Wojtyla A. Physical activity of polish adolescents and young adults according to IPAQ: a population based study. Annals of Agricultural and Environmental Medicine 2012;1(19):109-115.

31. Bergier M. Physical activity of students from selected countries. Studies review. Programmed Health Science. 2015;2(5):169-173.

32. Bednarek J, Pomykała S, Bigosińska M, Szyguła Z. Physical Activity of Polish and Turkish University Students as Assessed by IPAQ. Central European Journal of Sport Sciences \& Medicine. 2016;4(16):1322.

33. Rajappan R, Selvaganapathy K, Liew L. Physical Activity Level among University Students: a Cross Sectional Survey. In. J. Physiotherapy \&Research. 2015;3(6):1336-1343

34. Pon LW, Kandiah M, Mohd Nasir MT. Body image perception, dietary practices and physical activity of overweight and normal weight Malaysian female adolescents. Malaysia Journal of Nutrition 2004;10(2):131-147.

35. Abdulmajeed Al-Drees et al. Physical activity and academic achievement among the medical students: A cross-sectional study, Medical Teacher 2016;38(1):S66S72,

36. Elmagd MA, Mossa AH, Sami MM, Al Jadaan O, Salah M, Assistant EM et al. The Impact of Physical Activity on the Academic Performance among Medical and Health Sciences Students: Int. J of Physical Education, Sports and Health 2015;2(1):91-95.

37. Chung QE, Abdulrahman SA, Jamal Khan MK, Jahubar Sathik HB, Rashid A. The relationship between levels of physical activity and academic achievement among medical and health sciences students at cyberjaya University College of medical sciences. Malaysian J of Medical Sciences 2018;25(5):88-102.

38. Shephard RJ. Curricular physical activity and academic performance. Pediatric Exercise Science 1997;9:113126. 